Int. J. Electrochem. Sci., 14 (2019) 6077 - 6107

International Journal of

ELECTROCHEMICAL

SCIENCE

WWW.electrochemsci.org

Review

\title{
A Review of Lithium-Ion Battery Thermal Management System Strategies and the Evaluate Criteria
}

\author{
Shuting Yang ${ }^{1,2,3}$, Chen Ling ${ }^{1,2,3}$, Yuqian Fan ${ }^{4}$, Yange Yang ${ }^{1,2,3}$, Xiaojun Tan ${ }^{4, *}$, Hongyu Dong ${ }^{1,2,3, *}$ \\ ${ }^{1}$ School of Chemistry and Chemical Engineering, Henan Normal University, Xinxiang, Henan \\ Province, 453007, China; \\ ${ }^{2}$ National \& Local Engineering Laboratory for Motive Power and Key Materials, Xinxiang, Henan \\ Province, 453007, China; \\ ${ }^{3}$ Collaborative Innovation Center of Henan Province for Motive Power and Key Materials, Xinxiang, \\ Henan Province, 453007, China; \\ ${ }^{4}$ School of Intelligent Systems Engineering, Sun Yat-sen University, Guangzhou, Guangdong \\ Province, 510006, China; \\ *E-mail: tanxj@ mail.sysu.cn (X. Tan); donghy373@163.com (Y. Dong)
}

doi: $10.20964 / 2019.07 .06$

Received: 7 December 2018 / Accepted: 26 March 2019 / Published: 10 June 2019

Lithium-ion batteries have become widely used in energy storage systems. Since adverse operating temperatures can impact battery performance, degradation, and safety, achieving a battery thermal management system that can provide a suitable ambient temperature environment for working batteries is important. This paper provides a review based on previous studies, summarizes the electrical and thermal characteristics of batteries and how they are affected by the operating temperature, analyzes the relative merits and specific purposes of different cooling or heating methods, and provides many optimization methods. Moreover, because low power consumption, a high temperature regulation capacity, and excellent temperature uniformity are desired for every battery thermal management system, we also present control strategies that can contribute to thermal management. It is indispensable to establish criteria to evaluate battery thermal management systems. We subsequently summarize the characteristic parameters for the analysis of various battery thermal management system designs. Finally, we provide an outlook for the development of lithium-ion battery thermal management systems.

Keywords: Lithium-ion battery; thermal characteristic; thermal management system; control strategies; evaluate criteria.

\section{FULL TEXT}


(C) 2019 The Authors. Published by ESG (www.electrochemsci.org). This article is an open access article distributed under the terms and conditions of the Creative Commons Attribution license (http://creativecommons.org/licenses/by/4.0/). 